\title{
Soil water content measurement using polymer optical fibre Bragg gratings
}

Moura Mehravar BSc, MSc, PhD

Lecturer in Civil Engineering, College of Engineering and Physical Science, Aston University, Birmingham, UK (corresponding author:

m.mehravar@aston.ac.uk)

Hanrui Yang BSc, MSc, PhD

Associate Professor in Electrical Engineering, School of Automation

Engineering, Northeast Electric Power University, Jilin, China

David J. Webb BA, PhD

Professor of Photonics, College of Engineering and Physical Science, Aston University, Birmingham, UK
Wei Zhang BSc, MSc, PhD

Lecturer in Sensor Technology, School of Aerospace, Transport, and Manufacturing, Cranfield University, Cranfield, UK

Sina Fadaie Sestelani BSc, MSc

$\mathrm{PhD}$ candidate in Civil Engineering, College of Engineering and Physical Science, Aston University, Birmingham, UK

David N. Chapman BSc, PhD

Professor of Geotechnical and Underground Engineering, School of Engineering, University of Birmingham, Birmingham, UK

Measuring soil water content is crucially important and can affect soil strength, which is a key parameter in the analysis, design and monitoring of geo-structures. In this study, an optical fibre Bragg grating sensor inscribed in polymer optical fibre was developed, and for the first time, its ability to measure soil water content was investigated. The sensitivity of the sensor to different values of gravimetric soil water content under the different compaction conditions of loose and normal compaction was tested. The effect of soil temperature on the sensor's performance was considered. To assess the sensor's implementation, accuracy and reliability, a commercial soil water content probe (SM150), which measures volumetric soil water content was employed. The results indicate that the developed sensor, when calibrated correctly, is able to provide detailed data on any minor variation of soil water content (e.g. $0.5 \%$ ) with high precision. The outcomes of this study define an additional capability of the polymer optical fibre Bragg grating sensors, which is significantly important for the long-term performance monitoring of geo-structures.

Keywords: geo-structures/gravimetric soil water content/ground condition monitoring/polymer optical fibre Bragg grating (POFBG) sensor

\section{Notation}

e void ratio

$G_{\mathrm{S}} \quad$ specific gravity

$m_{\mathrm{s}} \quad$ mass of solid particles

$m_{\mathrm{w}} \quad$ mass of water

$n \quad$ porosity

$S_{\mathrm{r}} \quad$ degree of saturation

$T$ room/environment temperature

$T_{\text {soil }} \quad$ soil temperature

$V \quad$ total volume of soil

$V_{\mathrm{w}} \quad$ volume of water

$\theta \quad$ volumetric soil water content

$\lambda \quad$ sensor's wavelength

$\rho_{\mathrm{d}} \quad$ soil dry density

$\rho_{\text {solid }}$ density of solid particles

$\rho_{\mathrm{w}} \quad$ water density

$w \quad$ gravimetric soil water content

$w^{\prime} \quad$ gravimetric soil water content

$w_{0}^{\prime} \quad$ predefined gravimetric soil water content

\section{Introduction}

The performance and health condition of geotechnical assets such as retaining walls, pavements' subbase layers, embankments, cuttings, flood levees, slopes and earth dams are considerably important in both developed and developing societies. Precise prediction of the remaining service life of these assets can assist with taking the most suitable engineering intervention to avoid/eliminate catastrophic failures. As such, it is important to improve the understanding of the current condition of existing (often aging) infrastructure (Soga et al., 2015).

Generally, any failure or any condition that may cause failure in geo-structures, as well as their supporting ground, could potentially result in substantial damage to the infrastructure and disruption to their serviceability, and subsequently could affect society's function (Clarke et al., 2017; Curioni et al., 2018a; Du et al., 2016).

Changes in environmental (e.g. temperature and rainfall) and loading conditions alter soil properties including its mechanical properties, and, in some circumstances, this can lead to permanent changes of the ground. Soil is a multi-phase material, typically made of solid soil particles, water and air, with water significantly governing its behaviour. Variations in soil water content due to global climate change (e.g. extreme wet and dry weather cycles), seasonal fluctuations, or local site changes such as leakage from utility pipes, will affect the strength and mechanical properties of soil, leading to soil volume changes (shrink/swell mechanism) in fine-grained soils. Hence, measuring soil water content is of critical importance to evaluate soil strength, which is an important parameter in the analysis, design and monitoring of geo-structures. Often, very small changes in the soil water content over time can lead to the collapse of the ground and any supported infrastructure, 
resulting in damages and deterioration to assets (Gunn, 2015; Pritchard et al., 2014). The examples of such events are land sliding, the collapse of expansive clays and sinkholes. Additionally, several studies have shown that the soil water content has a significant effect on roads' and railways' subgrade performance (Bryson et al., 2012). In other words, strength and deformation of subgrade materials are directly associated with the soil water content; hence, this parameter must be accurately measured and monitored during the construction and service life of geo-structures (Mitchell and Soga, 2005).

In general, due to the complex, multi-phase, anisotropic and nonhomogenous nature of soils, the accurate measurement of their water content in the field is one of the greatest challenges that geotechnical engineers face during the site investigation stage of ground works as well as assessment and monitoring the condition of geo-structures during their service life.

The soil water content (sometimes known as moisture content) is expressed as either gravimetric basis $(w)$ or volumetric basis $(\theta)$. Soil gravimetric water content, $w$, is calculated as the ratio of the mass of the water contents to the mass of solid particles, while volumetric water content, $\theta$, is defined as the volume of water over the total volume in any given sample. For almost all basic relationships and calculations that are relevant to the strengths of soils in geotechnical engineering, the gravimetric variant is the preferred format as it can be accurately measured in the laboratory by the oven-drying method (BSI, 1999a) and can be directly used to describe the mechanical behaviour of the soil (Curioni, et al., 2018b). Volumetric and gravimetric soil water contents and their relationship can be expressed by Equations 1(a)-1(c).

$$
1(\mathrm{a}) . \quad w=\frac{m_{\mathrm{w}}}{m_{\mathrm{s}}}
$$

$$
\text { 1(b). } \theta=\frac{v_{\mathrm{w}}}{v}
$$

$$
1(\mathrm{c}) . \quad \theta=w \frac{\rho_{\mathrm{d}}}{\rho_{\mathrm{w}}}
$$

where $m_{\mathrm{w}}$ is mass of water; $m_{\mathrm{s}}$ is mass of soil (solid particles) in the sample; $V_{\mathrm{w}}$ is the volume of a soil mass that is occupied by water $\left(\mathrm{m}^{3}\right) ; V$ is the total volume of soil being investigated; $\rho_{\mathrm{d}}$ is the soil dry density; and $\rho_{\mathrm{w}}$ is the density of water.

To measure the soil water content, several different electrical sensors and cable systems have been developed, some of which are for use in the field, to monitor geo-structures. Often, these sensors are calibrated to measure the volumetric water content - that is, $\theta$ (Robinson et al., 2008). They are exposed to harsh environmental conditions (Huang
Chien et al., 2016), and therefore, the signal stability and system durability of the monitoring system are significantly important. Of all available geophysical techniques, the most notable is the time domain reflectometry or TDR (an electromagnetic-based method) that is used to measure $\theta$ at point locations in the field. However, this method suffers from a lack of accuracy, particularly at low moisture content, among other shortcomings, which limits its use (Curioni et al., 2018b). Other techniques such as neutron probe, or groundpenetrating radar, are costly and/or require expertise to set up and interpret, which may not be readily available. Additionally, they are limited to certain soil types or environmental conditions (Huisman et al., 2003). The study reported in this paper explores the feasibility of using a novel type of fibre optic sensing technique that lies outside the conventional electrical techniques, and therefore, does not suffer from the above limitations.

Over the past 40 years, fibre optic sensors have established themselves as a mature technology in applications where their unique properties give them advantages. These advantages include low fibre loss (enabling operation over multi-kilometre distances without intermediate amplification), their dielectric nature (granting them immunity to electromagnetic interference), their small size (enabling embedding in smart materials) and the robust nature of silica, allowing them to be used in harsh environments, for example, at temperatures of several hundred degrees Celsius. A particularly successful type of fibre optic sensor is the fibre Bragg grating (FBG). It takes the form of a laser-inscribed periodic axial spatial modulation of the fibre core refractive index, which has the effect of reflecting back down the fibre light with a wavelength determined by the period of the modulation and the value of the core index. From a sensing perspective, it is important to note that the period of the modulation and the fibre core index are both affected by any strain or temperature change applied to the fibre, resulting in a shift in the back-reflected wavelength. Hence, by monitoring the light reflected by the FBG, the strain or temperature of the fibre may be deduced.

While the majority of optical fibres are fabricated from silica, recent years have witnessed the development of the technology of FBGs recorded in polymer optical fibre (POF). A feature of one of the common polymers used - poly(methyl methacrylate) (PMMA) - is that it has an affinity for water, the absorption of which causes a swelling of the fibre and an increase in its refractive index, both of which contribute to a positive shift in the Bragg wavelength of any inscribed grating (Zhang and Webb, 2014). This is an equilibrium process where the amount of water absorbed by the fibre is determined by the degree of saturation of the fibre environment. The shift in the Bragg wavelength can therefore be used to determine the humidity of the air surrounding the fibre. The nominal response time for the equilibrium process of polymer optical fibre Bragg gratings (POFBGs) to humidity tends to be a few tens of minutes, and this does change considerably from fibre to fibre, which is related to the differing molecular weight distributions of the fibres; however, reduceddiameter (etched) fibres can have response times down to a few seconds (Rajan et al., 2013). 
Fibre optic sensors have been proposed for a number of geotechnical applications (Gong et al., 2019). Mainly, these have required the monitoring of strain, force or movement; a recent paper (Lopez Aldaba et al., 2018) describes a soil moisture sensor based on a fibre Fabry-Perot interferometer formed in the short length of a microstructured fibre coated with stannic oxide.

The aim of this feasibility study was to assess the ability and accuracy of POFBG sensors as the basis for an effective, accurate and inexpensive approach for soil condition monitoring by the measurement of gravimetric water content $(w)$. For the first time, the sensitivity of an FBG sensor fabricated in POF to soil water content changes was investigated. The sensor was tested at various values of gravimetric water content in different soil compaction conditions, and the obtained results were validated against traditional methods for soil water content measurement. Additionally, the effect of soil temperature on the sensor's response was considered and a temperature correction factor was determined.

\section{Sensor fabrication and packaging}

\subsection{POFBGs}

POFBGs have been extensively studied and utilised in many applications in the past 20 years, and yet, they also remain a topic of research, as people seek to exploit non-standard fibre types or develop new applications; an example of this is the development of grating technology in POFs that have different measures and sensitivities compared to silica fibre.

FBGs can be photo-inscribed in optical fibres made from a variety of polymers, including poly methyl methacrylate (PMMA), TOPAS, Zeonex, polycarbonate and CYTOP (Mehravar et al., 2019). The physical properties of polymers can obviously be very different to those of silica, and this leads to FBG sensors in the polymer fibre, having rather different features than those in the silica fibre. In particular, POFBGs can survive repeated straining in excess of 5\% and even over $10 \%$, depending on the fibre fabrication and drawing conditions. They have a lower elastic modulus compared to silicabased FBGs so when POFBGs are strained, the tension in the fibre is typically 25 times less, and so, the sensor exerts much less influence on its surrounding medium - this is important when FBGs are being used to sense strain in compliant materials.
POFs composed of PMMA have an affinity for water, which, when absorbed by the fibre, causes a swelling accompanied by an increase in refractive index, both of which result in a shift of the Bragg wavelength to higher values. The water absorption is a reversible process with the amount of water in the fibre being determined by the equilibrium relative humidity in the region surrounding the fibre. Considering the POFBG sensitivity to the relative humidity of its environment, this property also makes the POFBG sensitive to the concentration of water containing liquid surrounding the fibre. POFBGs have been shown to be highly effective at measuring very small $(10-100 \mathrm{ppm})$ quantities of water (Zhang et al., 2019).

\subsection{Sensor fabrication}

For the research presented in this paper, the sensor was created by inscribing an FBG with a nominal Bragg wavelength of $1531 \mathrm{~nm}$ in a $10 \mathrm{~cm}$ length of single-mode, step-index PMMA-based fibre using a $325 \mathrm{~nm}$ helium cadmium laser and the conventional phase mask approach - see Webb (2015). The fibre diameter was approximately $95 \mu \mathrm{m}$. Because the attenuation of PMMA-based POF is around $1 \mathrm{~dB} / \mathrm{cm}$ in this spectral region, the short sensing fibre was glued to a single-mode silica fibre (SMF-28) down-lead for connection to the interrogation system. The sensor was glued under a small amount of tension $(6 m \varepsilon)$ to an invar plate, on either side of the FBG, as shown in Figure 1, and leading to a final Bragg wavelength around $1537 \mathrm{~nm}$. This was done to prevent the fibre from experiencing significant strain-induced shifts in the Bragg wavelength. The metal plate holding the fibre was inserted into an $8 \mathrm{~mm}$ dia. steel tube to protect the sensing fibre from being damaged by contact with the soil. The end of the tube from which the fibre exits was sealed with glue, while the far end of the tube was covered with a metallic mesh $(0.3 \mathrm{~mm}$ holes on a $0.4 \mathrm{~mm}$ spacing). The mesh was chosen so as to prevent soil particles from entering the tube and potentially damaging the fibre but to allow the free passage of moisture (and the drainage of liquid water) to enable the air space within the tube to achieve an equilibrium with the surrounding soil - see Figures 2(a) and 2(b).

The POFBG was interrogated using a broadband source (Agilent 83437A) emitting around $50 \mu \mathrm{W}$ across the C-band, with the reflected signal from the POFBG being monitored using an I-Mon 52 USB spectrometer from Ibsen Photonics. This unit provides 512 measurement points across the spectral region $1510-1595 \mathrm{~nm}$.

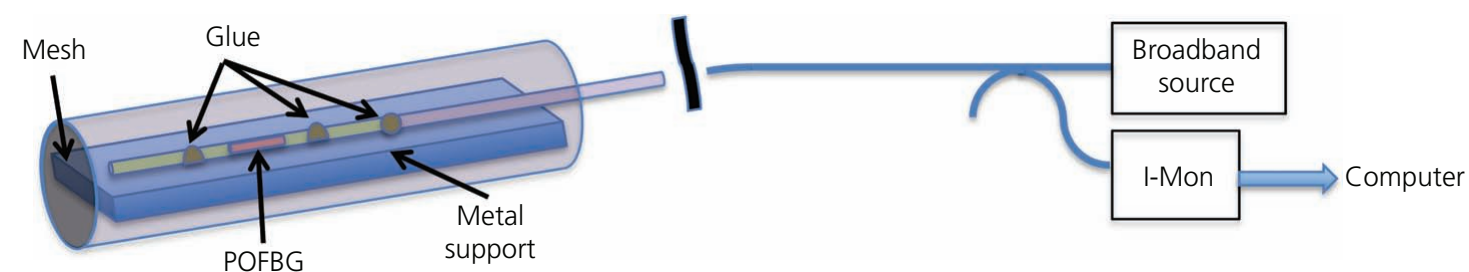

Figure 1. Sensor construction. POF length $=10 \mathrm{~cm}$, with $5 \mathrm{~mm}$ POFBG at centre. Invar support dimensions $=60 \times 6 \times 3 \mathrm{~mm}$ 


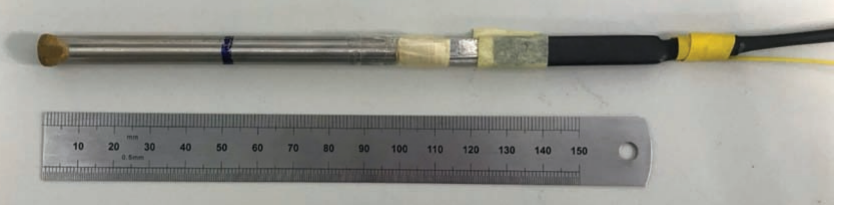

(a)

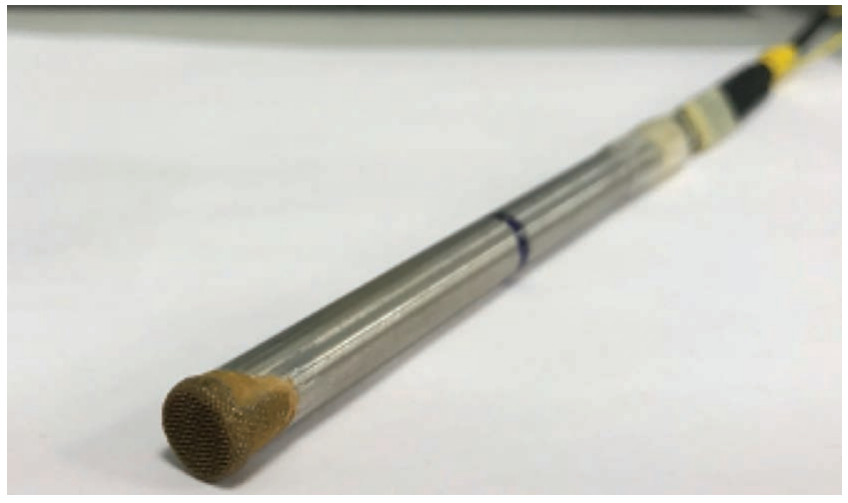

(b)

Figure 2. (a) The POFBG sensor packaging (outer diameter = $8 \mathrm{~mm}$ ). (b) Metallic mesh end cover to protect the sensor

In this study, the POFBG sensor was calibrated to measure/predict the variations of gravimetric soil water content $(w)$.

An important feature of FBG sensors that can significantly reduce the system cost when many measurement points are required is the ability to address multiple sensors with a single interrogation system using some combination of wavelength, time or spatial division multiplexing (Rao et al., 1996). A potential disadvantage of such sensors is the cross-sensitivity to temperature and strain. In their device, the authors effectively removed the sensitivity by fixing the fibre to a rigid metal plate that could not be significantly deformed by the forces likely to be experienced in our experiments. Temperature sensitivity was simply dealt with by separately monitoring the soil temperature (Section 3 ). Note that in a practical system, a simple solution to the sensor's crosssensitivity to temperature and strain would be to record a second FBG in the silica fibre inside the sensor housing. This grating would respond to temperature but not to water content, as silica is insensitive to humidity. The two grating responses could be distinguished using wavelength division multiplexing, as was done in a previous sensor used to monitor humidity and temperature.

\section{Effect of temperature on the sensor's performance}

While the literature shows reasonable agreement over the normalised strain sensitivities of various POFBGs, there is a much greater range of reported values when it comes to temperature. Partly, this is because in the early days of the technology, many measurements were made in the open-laboratory environment where the humidity was not controlled, leading to cross-sensitivity issues. In such experiments, sensitivities as high as $-360 \mathrm{pm}{ }^{\circ} \mathrm{C}^{-1}$ were reported (Liu et al., 2001). Consequently, the authors calibrated the temperature response of our sensor using an environmental chamber (Binder KBF 115) under constant humidity. The changes in wavelength were observed and recorded at increasing temperature (shown as $T$ in Figures 3(a) and 3(b)) increments of $2^{\circ} \mathrm{C}$. Figure 3(a) shows how the sensor responded to temperature changes at a constant relative humidity of $40 \%$. It can be observed that the sensor's wavelength decreases with increasing temperature (this arises because the negative thermo-optic coefficient of PMMA has a greater contribution to the wavelength shift than the thermal expansion of the fibre). To determine a temperature correction factor, for each temperature, the recorded data over the last $10 \mathrm{~min}$ were used to provide a mean wavelength (Figure 3(b)). Using a linear regression, a temperature correction factor of $0.11 \mathrm{~nm}$ per $1^{\circ} \mathrm{C}$ increment of temperature with regard to the normal room temperature of $20^{\circ} \mathrm{C}$ (as the reference temperature) was determined and applied to the results (Figure 3(b)).

\section{Soil properties}

All soil samples used in this study were silica sand (Leighton Buzzard sand), with the index data of the specific gravity of 2.66 and the nominal effective size of $0.63-0.85 \mathrm{~mm}$. A particle size distribution analysis was performed based on British Standard Institution (BSI, 1999a), and the results are presented in Figure 4. It is worth noting that from this point onwards, the term 'soil' refers to the silica sand that was used in this paper.

Two degrees of compactions, 'loosely' and 'normally' compacted, were used throughout the experiments. The following expressions (Equations 2 and 3) were used to determine the soil porosity, $n$ :

2. $n=1-\frac{\rho_{\mathrm{d}}}{\rho_{\text {solid }}}$

where

3. $\rho_{\text {solid }}=G_{\mathrm{s}} \times \rho_{\mathrm{w}}$

and $\rho_{\text {solid }}$ is the density of solid particles of soil; $\rho_{\mathrm{d}}$ is the soil density in dry condition; $\rho_{\mathrm{w}}$ is the density of water; $G_{\mathrm{s}}$ is the soilspecific gravity (2.66); and $n$ is the soil porosity. Table 1 shows the properties of the soil samples, including their porosity, used in this study.

\section{Experimental apparatus and soil sample preparation}

A standard proctor mould was employed to place and compact the soil samples in three equal layers. A minor modification was applied to the mould wherein the base plate of the mould was completely sealed to the cylinder to prevent any water leakage 


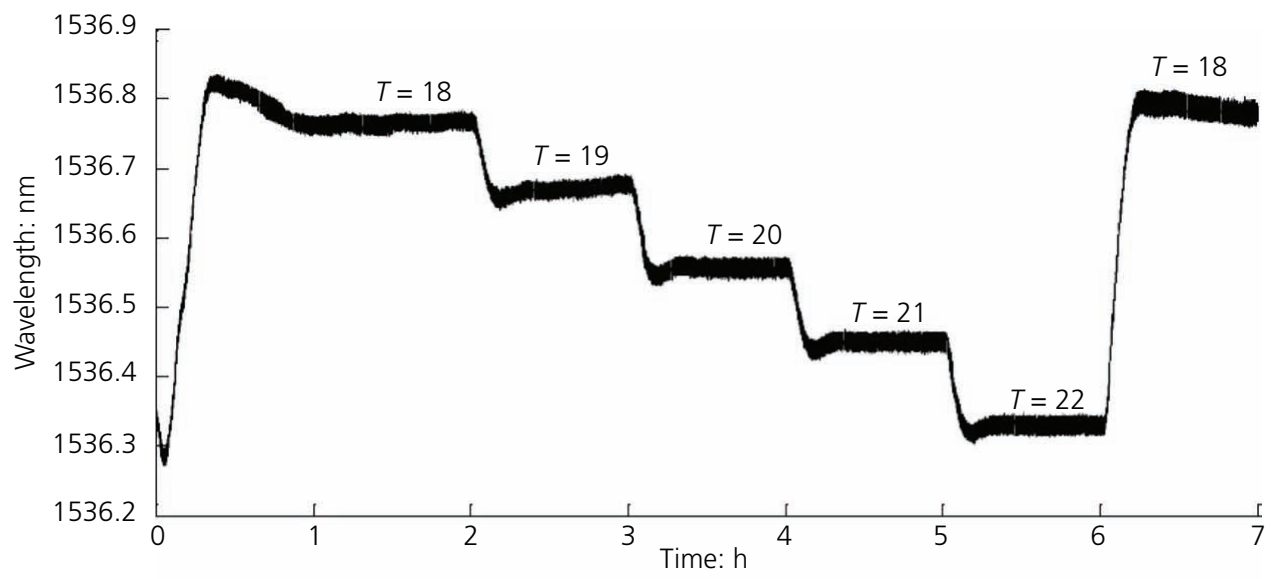

(a)

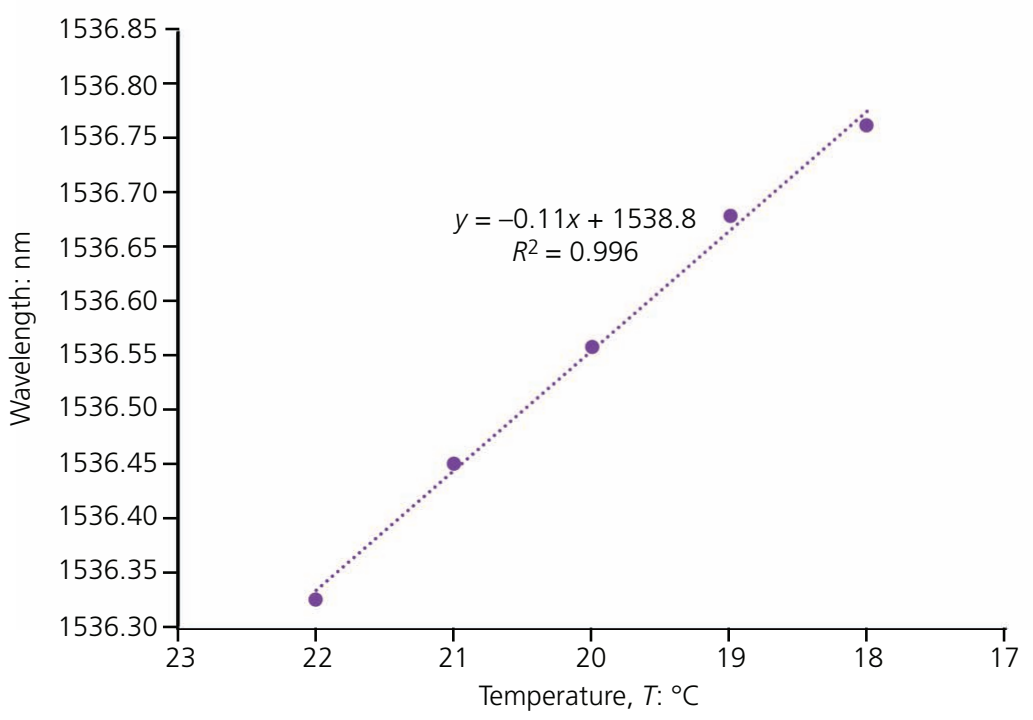

(b)

Figure 3. (a) The sensor's sensitivity to temperature changes in a constant relative humidity of $40 \%$. (b) The sensor's response to temperature changes in a constant relative humidity of $40 \%$

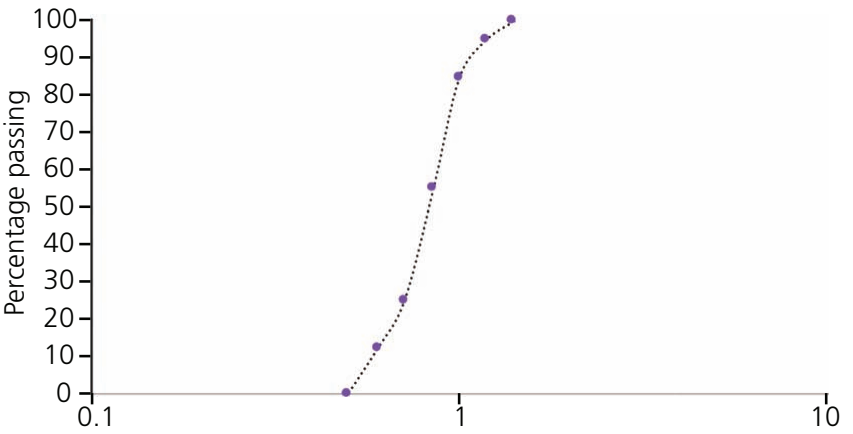

Figure 4. Soil particle size distribution curve (sieve analysis test) particularly for higher water content (Figure 5). The soil samples were oven-dried at $105^{\circ} \mathrm{C}$ overnight and then kept in the laboratory environment for at least $24 \mathrm{~h}$ until the soil moisture and temperature equalised with the laboratory condition. In this study, the authors refer to this state as the 'dry soil' condition. The soil samples in the laboratory were initially mixed at the dry soil condition to ensure that the individual components were as

Table 1. Soil properties

\begin{tabular}{|lcc|}
\hline Test & $\begin{array}{c}\text { Bulk (dry) density: } \\
\mathbf{g} / \mathbf{c m}^{\mathbf{3}}\end{array}$ & $\begin{array}{c}\text { Porosity, } \\
\mathbf{n} \text { : \% }\end{array}$ \\
\hline $\begin{array}{l}\text { Normally compacted (standard } \\
\text { proctor) }\end{array}$ & 1.69 & 36 \\
Loosely compacted & 1.55 & 42 \\
\hline
\end{tabular}




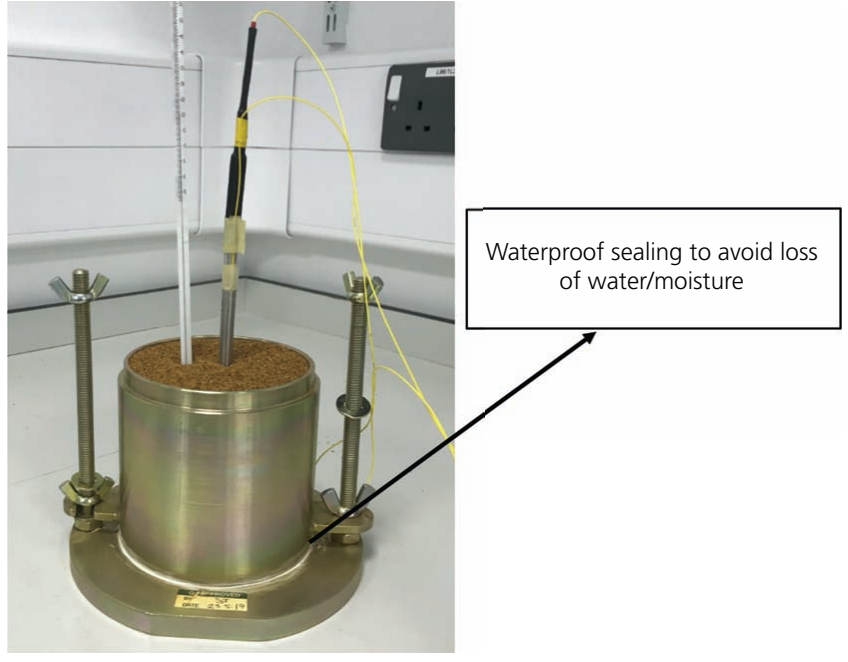

Figure 5. Standard proctor mould and soil sample

homogenous as practically possible. To generate the predefined different gravimetric water content, $w_{0}^{\prime}$, tap water was added using a pipette to the dry soil, and the soil-water mixture was mixed for a duration of 3 min using an electrical stand mixer. It should be noted that a fixed amount of dry soil was measured for the samples prepared in this study, while the amount of the added water was different; as the authors wanted to keep the soil dry unit weight constant in each sets of experiments.

Two sets of experiments were carried out based on the level of compactions. The first set was compacted according to BS 1377-4 standard (BSI, 1999b), using a standard proctor; the authors refer to this as the 'normally' compacted set or set 1 . Set 2 of the experiments was carried out under a loose compaction condition.

After the soil was sufficiently mixed with water, the samples in sets 1 and 2 were compacted in three equal layers in which each layer received 27 blows. Rammers weighing 2.5 and $0.5 \mathrm{~kg}$ were used for compaction purpose in sets 1 and 2, respectively. For both experiments, the drop height was $30 \mathrm{~cm}$ and the volume of the mould was kept constant at $1000 \mathrm{~cm}^{3}$. Various predefined soil water contents, $w_{0}^{\prime}$, were tested per each set of experiments (a summary of this information is presented in Table 2). To ensure the consistency of the experiments and their results, each test, for both sets, was repeated three times.
The POFBG sensor was inserted into the soil sample to a depth of $5 \mathrm{~cm}$ (Figure 5), and the sample was carefully wrapped using an airtight cling film to minimise evaporation during each test. The soil temperature varied between tests in the range $20-23^{\circ} \mathrm{C}$ due to room-temperature fluctuations. In each test, the soil temperature was recorded and the POFBG temperature calibration correction applied. To evaluate the sensor's performance, after each test, the moist soil sample was used to calculate the gravimetric soil water content $\left(w^{\prime}\right)$ using the oven-drying method (Table 3).

\section{Initial sensor response to dry-wet-dry soil environment}

As an initial test of the sensor response, the sensor was moved between dry and wet $\left(w_{0}^{\prime}=20 \%\right)$ in one of the samples in set 1 , with the results being presented in Figure 6. In this graph, the changes of the wavelength are presented against time. Immediately after the first dry phase, when the sensor was introduced to the wet soil, it can be observed that the measured wavelength increases towards a limiting value of $1537.82 \mathrm{~nm}$. This somewhat exponential response with a time constant of $1.5 \mathrm{~h}$ is the typical response of the sensor to a step change in humidity. The slow response is due to the time needed for the air space in the sensor tube to escape and the polymer fibre itself to reach equilibrium with the soil mixture. Depending on the application, the sensor can be redesigned to have a shorter response (as short as a few minutes or less) by reducing the volume of airspace around the fibre (Zhang et al., 2011). From $t_{1}$, the sensor's wavelength starts to rise once again until it reaches a new position at $t_{2}$. This second increase was unexpected, but the authors attribute it to a gradual movement of water through soil voids due to gravity. They expect that this would be less pronounced for the normally compacted samples given that the higher porosity of loosely compacted soil facilitates the gradual water movement through the initially homogenous soil medium, resulting in a variation of water content with depth and therefore a change in the measured wavelength. After $t_{2}$, the sensor had reached a stable stage and did not show any significant subsequent changes. The POFBG sensor was removed at $t_{3}$ and placed in a dry soil sample again, and it can be seen that there is a noticeable drop in the sensor's wavelength from $t_{3}$ until it gets to a steady wavelength that is almost equal to the recorded wavelength in the first dry phase. The slight difference between two dry phases is due to the change in the soil temperature (from 20 to $21^{\circ} \mathrm{C}$ ) over the period of the experiment $(\approx 9 \mathrm{~h})$.

Table 2. Parameters for each set of experiments used in this study

\begin{tabular}{|lcccccc} 
Test & $\begin{array}{c}\text { Number } \\
\text { of layers }\end{array}$ & $\begin{array}{c}\text { Number of } \\
\text { blows per layer }\end{array}$ & $\begin{array}{c}\text { Hammer } \\
\text { weight: } \mathbf{k g}\end{array}$ & $\begin{array}{c}\text { Drop } \\
\text { height: } \\
\mathbf{c m}\end{array}$ & $\begin{array}{c}\text { Proctor standard } \\
\text { mould volume: } \mathbf{c m}^{\mathbf{3}}\end{array}$ & $\begin{array}{c}\text { Predefined soil water } \\
\text { content, } \boldsymbol{w}_{\mathbf{0}}^{\prime}: \%\end{array}$ \\
\hline $\begin{array}{c}\text { Set 1: normally compacted } \\
\text { (standard proctor) }\end{array}$ & 3 & 27 & 25 & 30 & 1000 & $0.5,1,5,10,15,18$ \\
Set 2: loosely compacted & 3 & 27 & 5 & 30 & 1000 & $0.5,1,5,10,15,20$
\end{tabular}


Table 3. Results of all the tests for both sets 1 and 2

\begin{tabular}{|c|c|c|c|c|c|c|}
\hline \multirow[b]{2}{*}{$\begin{array}{l}\text { Test } \\
\text { number }\end{array}$} & \multicolumn{3}{|c|}{ Set 1: normally compacted } & \multicolumn{3}{|c|}{ Set 2: loosely compacted } \\
\hline & $\begin{array}{c}\text { Predefined soil } \\
\text { water content } w_{0}^{\prime} \text { : } \\
\%\end{array}$ & $\begin{array}{c}\text { Recorded } \\
\text { wavelength: } \\
\mathrm{nm}\end{array}$ & $\begin{array}{c}\text { Reference } w^{\prime} \text { by } \\
\text { oven-dried method: } \\
\%\end{array}$ & $\begin{array}{c}\text { Predefined soil } \\
\text { water content } w_{0}^{\prime} \text { : } \\
\%\end{array}$ & $\begin{array}{c}\text { Recorded } \\
\text { wavelength: } \\
\mathrm{nm}\end{array}$ & $\begin{array}{c}\text { Reference } w^{\prime} \text { by } \\
\text { oven-dried method: } \\
\%\end{array}$ \\
\hline 1 & 0.5 & 1537.65 & 0.47 & 0.5 & 1537.72 & 0.48 \\
\hline 2 & & 1537.64 & 0.48 & & 1537.66 & 0.38 \\
\hline 3 & & 1537.57 & 0.39 & & 1537.74 & 0.46 \\
\hline 1 & 1 & 1537.63 & 0.95 & 1 & 1537.67 & 0.79 \\
\hline 2 & & 1537.67 & 0.96 & & 1537.72 & 0.92 \\
\hline 3 & & 1537.65 & 0.97 & & 1537.75 & 0.93 \\
\hline 1 & 5 & 1537.69 & 4.87 & 5 & 1537.77 & 4.83 \\
\hline 2 & & 1537.72 & 4.89 & & 1537.79 & 4.84 \\
\hline 3 & & 1537.73 & 4.91 & & 1537.74 & 4.81 \\
\hline 1 & 10 & 1537.76 & 9.86 & 10 & 1537.81 & 9.85 \\
\hline 2 & & 1537.75 & 9.78 & & 1537.79 & 9.77 \\
\hline 3 & & 1537.74 & 9.73 & & 1537.82 & 9.84 \\
\hline 1 & 15 & 1537.78 & 14.40 & 15 & 1537.83 & 14.78 \\
\hline 2 & & 1537.81 & 14.52 & & 1537.84 & 14.81 \\
\hline 3 & & 1537.82 & 14.54 & & 1537.86 & 14.82 \\
\hline 1 & 18 & 1537.83 & 17.82 & 20 & 1537.91 & 19.64 \\
\hline 2 & & 1537.87 & 17.87 & & 1537.89 & 19.63 \\
\hline 3 & & 1537.86 & 17.74 & & 1537.88 & 19.64 \\
\hline
\end{tabular}

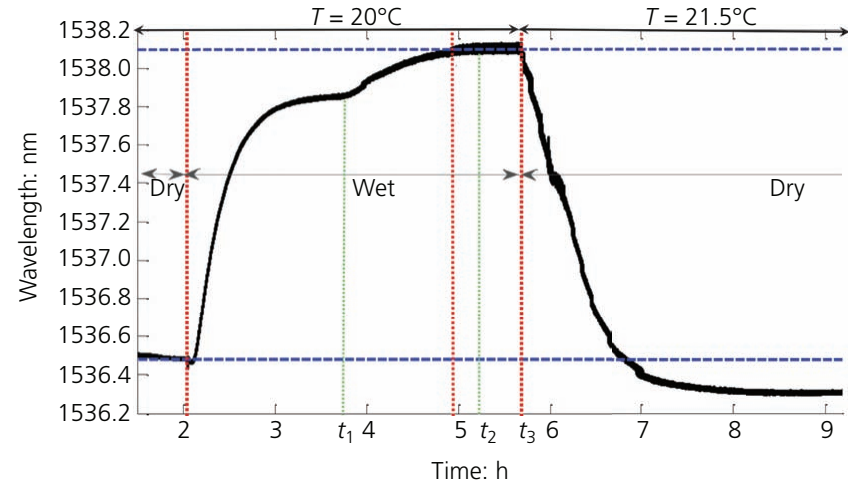

Figure 6. The measured/reflected wavelength from the POFBG sensor for $20 \%$ soil water content in the loosely compacted soil

\section{Results and discussion}

\subsection{Sensor response to changes in water content and in degree of compaction}

Samples with different water contents ranging from 0.5 to $20 \%$ for the loosely compacted and from 0.5 to $18 \%$ in the normally compacted soils were prepared in a controlled laboratory environment. The effect of different water contents in addition to the impact of compaction on the sensor's wavelength response was investigated. Each single test was repeated at least three times to reduce potential errors in the test procedure or data collection. In both sets (sets 1 and 2), samples were compacted up to nearsaturation condition. Therefore, it was impractical to perform the standard compaction test above $18 \%$ water content, as the samples become fully saturated at a water content of $21 \%$ (Table 1 and
Equation 6). The results of all the experiments for both sets, as well as their corresponding water content values (determined using the oven-drying method, $w^{\prime}$ ), are shown in Table 3 . It should be noted that the temperature correction factor of $0.11 \mathrm{~nm}$ per $1{ }^{\circ} \mathrm{C}$ increment of temperature has been applied to all recorded wavelengths. These values were obtained from the average sensor's response in its last 15 min per each sample.

Figures 7 and 8 demonstrate the sensor's response to various soil water contents for all samples in sets 1 and 2, respectively. Each test was repeated three times, and all three measurements per each water content in sets 1 and 2 are presented in Figures 7 and 8, respectively. It is evident that the sensor is able to detect small changes in soil water content even as low as $0.5 \%$.

Out of a total of 36 tests, the data from 3 tests were considered out of the range and therefore excluded from the rest of analysis. These corresponded to those samples in set 1 where $w_{0}^{\prime}=0.5$ and in set 2 where $w_{0}^{\prime}=0.5$ and $1 \%$, (shown by red-filled circle symbols in Figures 7 and 8). The decision to consider these out of the range were justified by comparing the values with those measured by the oven-drying method $\left(w^{\prime}\right)$. The most likely reason for these differences was the loss of added water during sample preparation.

Using the mean values of each test, the sensor's sensitivity to the soil water content were estimated as $0.011 \pm 0.001 \mathrm{~nm} /$ per cent and $0.0081 \pm 0.0003 \mathrm{~nm} /$ per cent for normally and loosely compacted samples, respectively. Additionally, the standard error values in water contents were calculated as $\frac{0.009}{0.011}=0.82 \%$ for loosely compacted and $\frac{0.005}{0.008}=0.63 \%$ for normally compacted samples. The relatively low values of standard error indicate the 


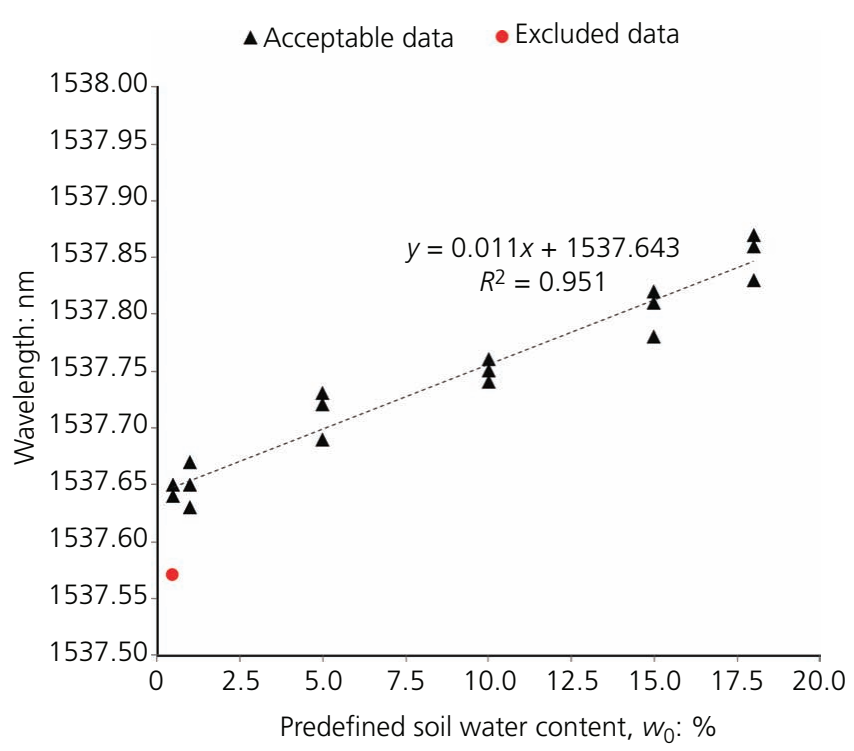

Figure 7. POFBG response to different gravimetric soil water content in the normally compacted soil samples

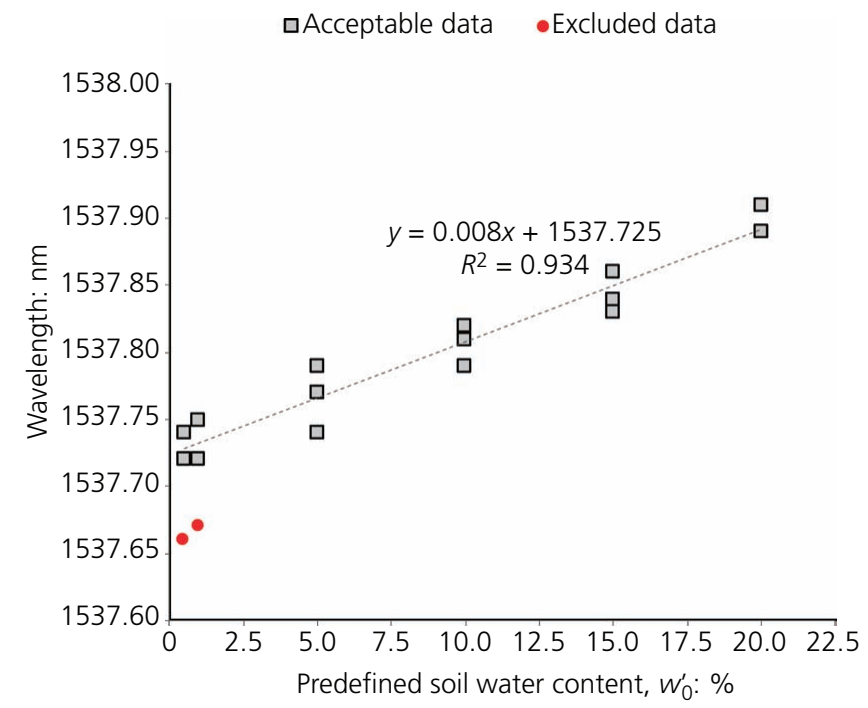

Figure 8. POFBG response to different gravimetric soil water content in the loosely compacted soil samples

consistency of the obtained data throughout the test and demonstrate the ability and accuracy of the developed sensor for soil water content measurement.

Additionally, it can be observed that in both sets of experiments, a linear relationship can be established between the soil water content, $w$, and the sensor's wavelength, $\lambda$, which can be expressed by Equations 4 and 5 for loosely and normally compacted samples, respectively. This further demonstrates the suitability of the sensor for use in this application.

$$
w(\%)=\frac{\lambda+0.11\left(T_{\text {soil }}-20\right)-1537.72}{0.01}
$$

4. $\times 100$ in loosely compacted samples

$$
\begin{aligned}
w(\%)= & \frac{\lambda+0.11\left(T_{\text {soil }}-20\right)-1537.64}{0.01} \\
& \times 100 \text { in normally compacted samples }
\end{aligned}
$$

Note that in the above equations, $T_{\text {soil }}$ is in degrees Celsius and these equations are valid to predict the soil water content up to near-saturation condition in the sandy soils presented in Table 1.

For comparison, the sensor's response to changes of water content for both compaction conditions are shown in Figure 9. The sensor's wavelength, $\lambda$, in set 1 is smaller than those of set 2 , which can be explained by the smaller porosity in the normally compacted samples compared to the loosely compacted ones and the fact that in more compacted soil, where the porosity is lower, less water content (soil moisture) is required to make the sample fully saturated. Using Equation 6, the degree of saturation for all samples with different moisture contents is calculated and presented in Figure 10. This equation explains the relationship between the soil water content, $w$, soil void ratio, $e$, the degree of saturation, $S_{\mathrm{r}}$, and specific gravity, $G_{\mathrm{s}}$ :

6. $S_{\mathrm{r}} \times e=w \times G_{\mathrm{s}}$

\subsection{Evaluation of the sensor's performance}

For comparison and completeness, a commercial soil water content measurement sensor, the SM150 probe (Figure 11) was used to measure the volumetric soil water content $(\theta)$ in the samples tested above. The probe measures volumetric soil water

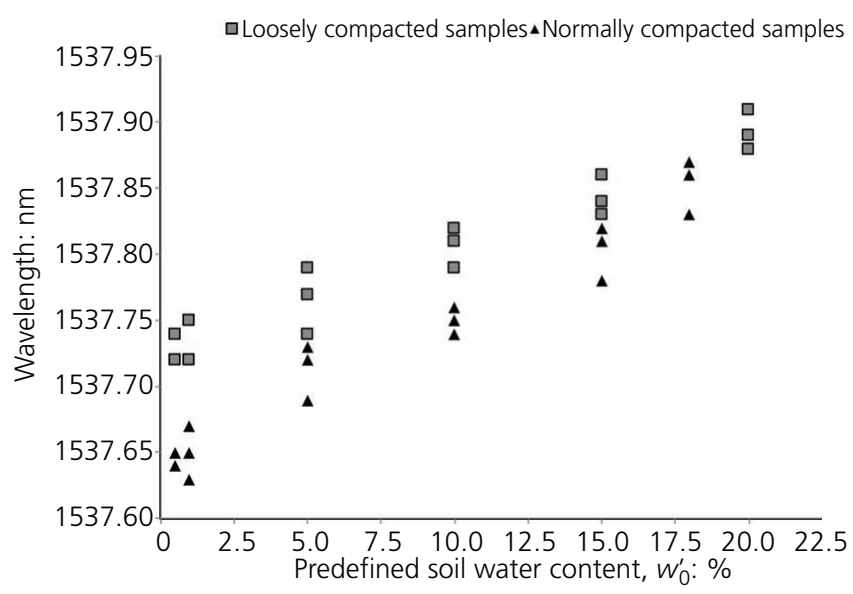

Figure 9. Comparison of the sensor's response in normally and loosely compacted samples 
content by responding to changes in the apparent dielectric constant of the moist soil. The probe was placed in four different locations of the sample in close proximity to and at the same depth where the POFBG sensor was buried. Table 4 shows the measured data by the probe in a number of the tests for the normally compacted samples. The probe measurement was recorded when the POFBG sensor reached an equilibrium and a constant wavelength was observed.

In Table 4, there are no data for the soil water content of 0.5 and $1 \%$ as the probe was not sensitive to any soil water content less than $3 \%$. An average of the four readings by the probe was calculated and converted to gravimetric soil water content using Equation 1c and then compared with the oven-drying method $\left(w^{\prime}\right)$, as well as the POFBG sensor predictions (Equation 5) - the results are presented in Table 5. Both absolute and percentage errors using the two different measurement tools with respect to the oven-drying method $\left(w^{\prime}\right)$ are calculated and presented. Error ${ }_{1}$ and Error $_{2}$ are the absolute error for water content measured by POFBG (Equation 5) and the probe, respectively. While the percentage error (\%) value provides a base for relative comparison, the absolute error offers a better context for the error in this case since it can provide a clearer and direct knowledge of the expected accuracy in the measurements.

Generally, the probe underestimates the gravimetric water content and in particular for low water content where there is a significant percentage error $(>60 \%)$. The probe was not able to measure soil water content less than $3 \%$. Additionally, it is worth noting that the corresponding absolute error (mean error) is not within the approximately $3 \%$ water content error that is normally considered as an accuracy range of soil water content sensors (Curioni et al., 2018a). On the other hand, it can be seen from Table 4 that the average percentage error predicted by Equation 5 is less than $9 \%$ and the corresponding absolute value is less than $1.5 \%$.

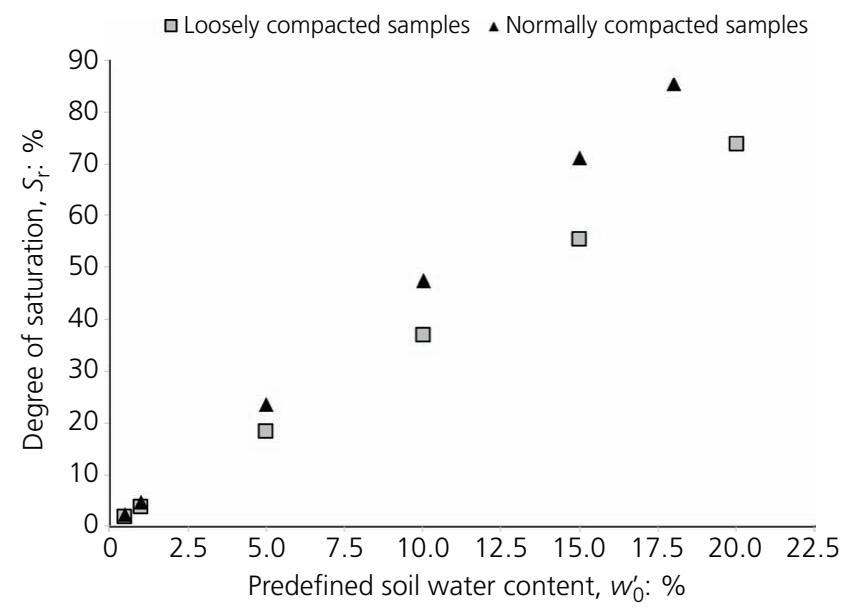

Figure 10. Saturation degree at each water content in loosely and normally compacted samples

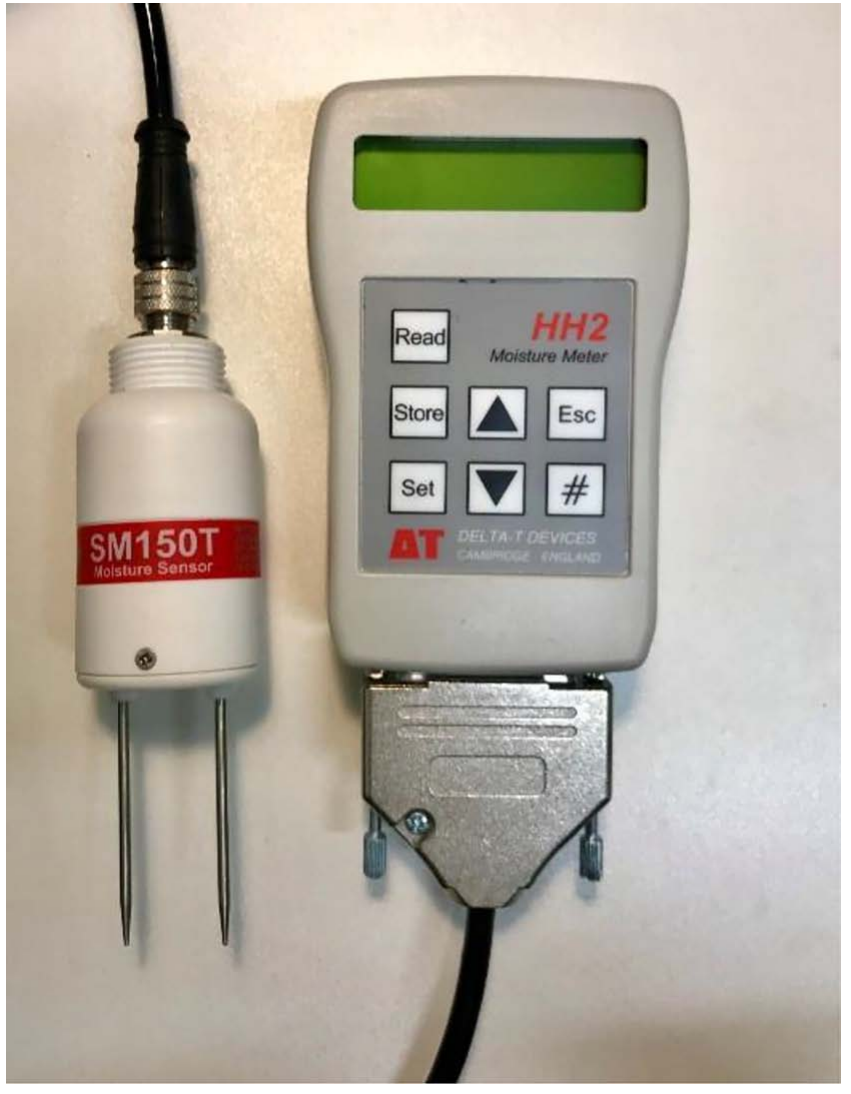

Figure 11. SM150 probe to measure the volumetric soil water content

Table 4. Measured $\theta$ by the probe at four different locations in normally compacted samples

\begin{tabular}{lc}
$\begin{array}{l}\text { Reference } w^{\prime} \text { by oven-dried } \\
\text { method (gravimetric water } \\
\text { content): \% }\end{array}$ & $\begin{array}{c}\theta \text { measured by the SM150 } \\
\text { probe (volumetric water } \\
\text { content): \% }\end{array}$ \\
\hline 4.87 & $3.1,3.1,2.9,3.2$ \\
9.86 & $5.6,5.7,5.5,5.3$ \\
14.40 & $20.6,20.9,20.3,20.2$ \\
17.82 & $27.4,26.8,28.3,27.5$ \\
\hline
\end{tabular}

\section{Summary and conclusions}

A continuous monitoring of changes in ground conditions by measuring the variations of different ground properties such as water content is vital to analyse the stability of the ground and geotechnical assets, which facilitates the prediction of their deterioration processes. The soil water content is linked with many critical properties of soils including their strength. There are several techniques available to measure the soil water content; however, they each suffer from a number of drawbacks ranging from high costs to the lack of accuracy. This motivated the authors to develop a resilient and novel POFBG sensor to accurately measure the soil water content. In this study, for the first time, the sensitivity of an FBG sensor fabricated in POF to the soil water content was investigated. The authors focused 
Table 5. Validation of the SM150 probe measurements for a selected number of normally compacted samples in partially saturated samples

\begin{tabular}{|c|c|c|c|c|c|}
\hline $\begin{array}{l}\text { Soil sample } \\
\text { condition }\end{array}$ & $\begin{array}{l}\text { Reference } w^{\prime} \text { by oven-dried } \\
\text { method: \% }\end{array}$ & $\begin{array}{l}w \text { estimated by POFBG } \\
\text { (Equation 5): \% }\end{array}$ & Error $_{1}{ }^{a}$ & $\begin{array}{c}w \text { by the SM150 } \\
\text { probe: } \%\end{array}$ & Error $_{2}{ }^{\mathrm{a}}$ \\
\hline \multirow[t]{4}{*}{$\begin{array}{l}\text { Normally } \\
\text { compacted soil }\end{array}$} & 4.87 & 5 & $\begin{array}{l}0.13 \\
{[2.67]}\end{array}$ & 1.82 & $\begin{array}{l}-3.00 \\
{[62.24]}\end{array}$ \\
\hline & 9.86 & 12 & $\begin{array}{l}2.14 \\
{[21.7]}\end{array}$ & 3.27 & $\begin{array}{l}-6.56 \\
{[66.73]}\end{array}$ \\
\hline & 14.40 & 14 & $\begin{array}{l}0.40 \\
{[2.8]}\end{array}$ & 12.13 & $\begin{array}{l}-2.27 \\
{[15.76]}\end{array}$ \\
\hline & 17.82 & 19 & $\begin{array}{l}1.18 \\
{[6.62]}\end{array}$ & 16.27 & $\begin{array}{l}-1.48 \\
{[8.34]}\end{array}$ \\
\hline Mean error & - & - & $\begin{array}{l}1.21 \\
{[8.44]}\end{array}$ & - & $\begin{array}{l}-3.33 \\
{[38.26]}\end{array}$ \\
\hline
\end{tabular}

${ }^{\text {a }}$ Values in square brackets are \% error

on calibrating the POFBG sensor to detect the small changes on soil water content rather than the absolute value since a variation of the soil water content over time is more critical for the geomechanical behaviour of soils. The sensor was properly packaged and buried vertically in a set of sandy soil samples. The effect of soil temperature on the sensor's response was considered, and a temperature correction factor was determined and applied to all measurements.

The sensor was tested at two different compaction soil conditions of 'loosely' and 'normally' compacted soils, and its sensitivity and response to the various values of gravimetric soil water content was investigated. The proposed sensor showed ability to detect changes, even as low as $0.5 \%$, in the soil water content, which is crucial to monitor geo-structures and ground conditions in general. Additionally, the results showed that the sensor is highly sensitive to different soil porosities. It was observed that the relationship between the water content and the sensor's wavelength in both compaction conditions is linear, which can facilitate the estimation of the soil water content up to a nearsaturation condition for each soil compaction.

Moreover, the accuracy, reliability and advantages of the sensor's prediction was evaluated by comparing its prediction with commercial soil water content probe (SM150). The measurements by both sensing devices were assessed against the oven-drying method using absolute and percentage errors. The comparison results indicated that the developed POFBG sensor's prediction and its sensitivity to water content variation is more accurate than the commonly used commercial probe with a mean absolute error of $1.21 \%$.

The proposed sensor in this study can be developed and employed in geo-structures as an early warning system for monitoring geotechnical assets to detect any changes caused by changes in the soil water content (e.g. due to extreme weather condition or a leaking pipe). The use of the POFBG sensor will facilitate in situ measurement, allowing for the continuous monitoring of the change of water content at multi-points and, in most cases, will eliminate the need for a long and tedious sampling process. Integrating the data collected from this sensor with other key parameters of soil strength will provide a comprehensive picture of the system (soil and infrastructure) where, currently, such integrated system does not exist. The integrated model can provide adequate information on the structural integrity and stability of the system, thereby enabling the decision makers to prevent or tackle potential problems.

However, the sensor's performance should be further investigated by conducting additional laboratory and field trials including different soil types (e.g. clay, clayey sand) and soil properties (e.g. different compaction conditions) to ensure its reliability. The response time of the sensor should also be redesigned and shortened for those applications where the small changes of water content in a short time is critical. The current response time of the sensor is suitable for those applications where a long-term dynamic monitoring of the groundwater table is required for their maintenance such as a slope's stability and groundwater table variation monitoring. Furthermore, the sensor's stability in a longer time from a few days to a few months needs to be tested in the laboratory as well as in the field.

\section{Acknowledgements}

The first author would like to thank the Aston Institute of Materials Research (AIMR) for financial support. The second author gratefully acknowledges a visiting scholarship supported by the Chinese Scholarship Council. The authors would like to thank Prof GangDing Peng of the University of New South Wales for the supply of the polymer fibre.

\section{REFERENCES}

Bryson LS, Jean-Louis M and Gabriel C (2012) Determination of in situ moisture content in soils from a measure of dielectric constant. International Journal of Geotechnical Engineering 6(2): 251-259, https://doi.org/10.3328/IJGE.2012.06.02.251-259.

BSI (1999a) BS 1377-2: Methods of test for soils for civil engineering purposes, part 2: classification tests. BSI, London, UK. 
BSI (1999b) BS 1377-4: Methods of test for soils for civil engineering purposes, part 4: compaction - related tests. BSI, London, UK

Byoungho L (2003) Review of the present status of optical fibre sensors. Optical Fiber Technology 9(2): 57-79, https://doi.org/10.1016/S10685200(02)00527-8.

Clarke BG, Magee D, Dimitrova V et al. (2017) A decision support system to proactively manage subsurface utilities. Proceedings of the International Symposum for Next Generation Infrastructure 2017 Conference. ISNGI, London, UK, pp. 99-108.

Curioni G, Chapman DN, Pring LJ, Royal AC and Metje N (2018) Extending TDR capability for measuring soil density and water content for field condition monitoring. Journal of Geotchnical and Goenvironmental Engineering (ASCE) 144(2): 04017111, https://doi. org/10.1061/(ASCE)GT.1943-5606.0001792.

Curioni G, Chapman DN, Royal AC et al. (2019) Time domain reflectometry (TDR) potential for soil condition monitoring of geotechnical assets. Canadian Geotechnical Journal 56(7): 942-955, https://doi.org/10.1139/cgj-2017-0618.

Delta-T Devices (2017) User Manual for HH2. Delta-T Devices Ltd, Cambridge, UK.

Du H, Dimitrova V, Magee D et al. (2016) An ontology of soil properties and processes. In International Semantic Web Conference. Springer, Cham, Manhattan, USA, pp. 30-37.

Gong H, Kizil MS, Chen Z et al. (2019) Advances in fibre optic based geotechnical monitoring systems for underground excavations. International Journal of Mining Science and Technology 29(2) 229-238, https://doi.org/10.1016/j.ijmst.2018.06.007.

Gunn DA, Chambers JE, Uhlemann S et al. (2015) Moisture monitoring in clay embankments using electrical resistivity tomography. Construction and Building Materials 92: 82-94, https://doi.org/10. 1016/j.conbuildmat.2014.06.007.

Harbach NG (2008) Fibre Bragg Gratings in Polymer Optical Fibres. $\mathrm{PhD}$ thesis, École Polytechnique Fédérale de Lausanne, Lausanne, Switzerland.

Huang Chien AB, Wang CC, Lee JT and Ho YT (2016) Application of FBG-based sensors to ground stability monitoring. Journal of Rock Mecanics and Geotechnical Engineering 8(4): 513-520, https://oi. org/10.1016/j.jrmge.2016.01.007.

Huisman JA, Hubbard SS, Redman JD and Annan AP (2003) Measuring soil water content with ground penetrating radar. Vadoze Zone Journal 2(24): 476-491, https://doi.org/10.2136/vzj2003.4760.

Liu HY, Peng GD and Chu PL (2001) Thermal tunning of polymer optical fibre Bragg grating. IEEE Photonics Technology Letters 13: 824-826, https://doi.org/10.1109/68.935816.

Lopez Aldaba A, Lopez-Torres D, Campo-Bescó MA et al. (2018) Comparison between capacitive and microstructured optical fiber soil moisture sensors. Applied Science 8(9): 1-12, https://doi.org/10.3390/ app8091499.

Mehravar M, Yang H, Zhang W and Webb D (2019) Ground-water monitoring using polymer optical fibre Bragg gratings. In Seventh European Workshop on Optical Fibre Sensors. International Society for Optics and Photonics Bellingham, Washington USA, vol. 11199, p. 111991M.

Mitchell J and Soga K (2005) Fundamentals of Soil Behaviour. John Wiley and Sons, Inc., Hoboken, NJ, USA, p. 557.

Pritchard OG, Hallet SH and Farewell TS (2014) Soil impacts on UK infrastructure: current and future climate. Proceedings of the Institution of Civil Engineers - Engineering Sustainability 167(4): 170-184, https://doi.org/10.1680/ensu.13.00035.

Rajan G, Mohd Noor MY, Liu B and Ambikairaja E (2013) A fast response intrinsic humidity sensor based on an etched singlemode polymer fibre Bragg grating. Sensors and Actutators A: Physical 203: 107-111.

Rao YJ, Lobo Ribeiro AB, Jaclspm DA, Zhang L and Bennion I (1996) Simultaneously spatial-, time-, and wavelength-division multiplexed in-fiber Bragg grating sensor network. In Distributed and Multiplexed Fiber Optic Sensors VI (Kersey AD and Dakin JP (eds)). SPIE, Bellingham, Washington USA, pp. 23-30.

Robinson DA, Campbel CS, Hopmans JW et al. (2008) Soil moisture measurement for ecological and hydrological watershed-scale: a review. Vadose Zone Journal 7(1): 358-389, https://doi.org/10.2136/ vzj2007.0143.

Robock A (2014) Hydrology, floods and drought: soil moisture. In Encylopedia of Atmospheric Science, 2nd edn., pp. 232-239.

Soga K, Kwan V, Pelecanos L et al. (2015) The role of distributed sensing in understanding the engineering performance of geotechnical structures. Proceedings of the of the XVI European Conference on Soil Mechanics and Geotechnical Engineering, ECSMGE 2015 Geotechnical Engineering for Infrastructure and Development, vol. 1, pp. 13-48.

Webb DJ (2015) Fibre Bragg gratting sensors in polymer optical fibres. Measurement Science and Technology 26(9): 092004

Zhang W, Webb DJ, Lao L et al. (2019) Water content detection in aviation fuel by using PMMA based optical fiber grating. Sensors and Actuators B: Chemical 282: 774-779, https://doi.org/10.1016/j.snb. 2018.11.134.

Zhang W and Webb D (2014) Humidity responsivity of poly(methyl methacrylate)-based optical fiber Bragg grating sensors. Optic Letters 39(10): 3026-3029, https://doi.org/10.1364/OL.39.003026.

Zhang W, Webb DJ and Peng GD (2011) Imprived time response for polymer fibre Bragg grating based humidity sensors. In 21st International Conference on Optical Fibre Sensors (OFS21). International Society for Optics and Photonics, Bellingham, Washington USA, vol. 7753, p. 77533M.

\section{How can you contribute?}

To discuss this paper, please email up to 500 words to the editor at journals@ice.org.uk. Your contribution will be forwarded to the author(s) for a reply and, if considered appropriate by the editorial board, it will be published as discussion in a future issue of the journal.

Proceedings journals rely entirely on contributions from the civil engineering profession (and allied disciplines). Information about how to submit your paper online is available at www.icevirtuallibrary.com/page/authors, where you will also find detailed author guidelines. 